\title{
Robotic and Endoscopic Thyroid Surgery: Evolution and Advances
}

\author{
Kyung Tae ${ }^{1}$ Y Yong Bae $\mathrm{Ji}^{1} \cdot$ Chang Myeon Song ${ }^{1} \cdot$ Junsun Ryu ${ }^{2}$ \\ ${ }^{1}$ Department of Otolaryngology-Head and Neck Surgery, Hanyang University College of Medicine, Seoul; \\ ${ }^{2}$ Department of Otolaryngology-Head and Neck Surgery, Center for Thyroid Cancer, National Cancer Center, Goyang, Korea
}

\begin{abstract}
To minimize surgical morbidity and neck scarring, minimally invasive thyroidectomy and robotic/endoscopic thyroidectomy via cervical, axillary, anterior chest, breast, postauricular or transoral approaches have been developed over the past 20 years. In this article, we review the evolution of robotic and endoscopic thyroid surgery and recent advances. Among remote access approaches, the gasless transaxillary approach, bilateral axillo-breast approach, postauricular facelift approach, and transoral vestibular approach are in common use today. Each procedure has its own advantages and disadvantages. Therefore, we need to understand these advantages and limitations, and to select the appropriate method for each patient. The most significant advantage of remote access thyroidectomy is its excellent cosmesis. The complication rate is similar in patients undergoing a remote access approach and those undergoing conventional surgery if the former is performed by experienced surgeons. Operative time is significantly longer in remote access thyroidectomy. In conclusion, remote access thyroidectomy is feasible and its outcomes are comparable to those of conventional transcervical thyroidectomy in highly selected patients.
\end{abstract}

Keywords. Robotic Thyroidectomy; Endoscopic Thyroidectomy; Remote Access Thyroidectomy; Minimally Invasive Thyroidectomy; Thyroid Neoplasms

\section{INTRODUCTION}

Minimally invasive and remote access thyroidectomy using endoscopy or surgical robots has gained in popularity for the treatment of thyroid tumors. It has been developed to minimize surgical morbidity and to avoid or hide the visible neck scarring that is one of the drawbacks of conventional trans-cervical thyroidectomy, because neck scarring is a major concern in thyroid surgery, especially in young women. Endoscopic and robotic thyroidectomy via cervical, axillary, anterior chest, breast, postauricular or transoral approaches has been developed over the past 20 years [1-30] and has been recently refined. Here, we review the evolution of robotic and endoscopic thyroid surgery and recent advances.

- Received May 24, 2018

Accepted August 3, 2018

- Corresponding author: KyungTae

Department of Otolaryngology-Head and Neck Surgery, Hanyang

University College of Medicine, 222-1Wangsimni-ro, Seongdong-gu,

Seoul 04763, Korea

Tel: +82-2-2290-8585, Fax: +82-2-2293-3335

E-mail: kytae@hanyang.ac.kr

\section{CLASSIFICATION OF ROBOTIC/ENDOSCOPIC THYROIDECTOMY}

Robotic and endoscopic thyroidectomy can be classified according to the use of carbon dioxide $\left(\mathrm{CO}_{2}\right)$ gas insufflation and the site of incision (Table 1). Methods of $\mathrm{CO}_{2}$ insufflation include the cervical approach, axillary approach, breast approach, anterior chest approach, transoral approach and various axillo-breast approaches such as the axillo-bilateral breast approach (ABBA), bilateral axillo-breast approach (BABA), and unilateral or bilateral axillo-breast approach. The gasless method includes minimally invasive video-assisted thyroidectomy (MIVAT), the anterior chest approach, axillary approach, postauricular facelift approach and transoral approach. There are also various modifications and combinations of these approaches.

\section{THE EVOLUTION OF ROBOTIC/ENDOSCOPIC THYROIDECTOMY}

The first endoscopic thyroidectomy was performed in 1997 us-

Copyright @ 2019 by Korean Society of Otorhinolaryngology-Head and Neck Surgery.

This is an open-access article distributed under the terms of the Creative Commons Attribution Non-Commercial License (http://creativecommons.org/licenses/by-nc/4.0)

which permits unrestricted non-commercial use, distribution, and reproduction in any medium, provided the original work is properly cited. 
Table 1. Classification of robotic and endoscopic thyroidectomies

\begin{tabular}{l}
\hline $\mathrm{CO}_{2}$ insufflation method \\
Cervical approach \\
Anterior chest approach \\
Axillary approach \\
Breast approach with parasternal port \\
Axillo-breast approach \\
Axillo-bilateral breast approach \\
Bilateral axillo-breast approach \\
Unilateral/bilateral axillo-breast approach \\
Transoral approach \\
Gasless method \\
Minimally invasive video-assisted thyroidectomy \\
Anterior chest approach \\
Video-assisted neck surgery \\
Axillary approach \\
Axillary approach with anterior chest port \\
Single incision axillary approach \\
Gasless unilateral axillo-breast or axillary approach \\
Facelift (retroauricular) approach \\
Transoral approach \\
\hline
\end{tabular}

ing a cervical approach with $\mathrm{CO}_{2}$ insufflation [1]. In 1999, Miccoli et al. [2] developed MIVAT without $\mathrm{CO}_{2}$ insufflation, to avoid $\mathrm{CO}_{2}$-related complications. Since then, various remote-access thyroidectomy methods via axillary, breast, anterior chest, postauricular, and transoral routes have been developed to hide neck scarring.

\section{The cervical approach}

The cervical approach involves three to four small ports including a 12-mm endoscopic port and two to three operating instrument ports in the anterior or lateral neck (Fig. 1A) [1,3]. The working space is maintained by $\mathrm{CO}_{2}$ insufflation at low pressure. MIVAT is a direct access method using a 1.5-2 cm central neck incision without $\mathrm{CO}_{2}$ insufflation (Fig. 1B) [2]. The main advantage of MIVAT is that it is a minimally invasive procedure rather than that it improves cosmesis because it ultimately leaves a scar in the neck although one that is smaller than in the conventional

\section{H I G H L I G H T S}

- Minimally invasive video-assisted thyroidectomy, transaxillary, bilateral axillo-breast approach, facelift and transoral approaches are in common use today.

- Remote access thyroidectomy is feasible and comparable to conventional thyroidectomy.

- The most important advantage of remote access thyroidectomy is its excellent cosmesis.

- The various approaches have their own advantages and disadvantages.

- Strict patient selection criteria are important. procedure. Many workers have reported that MIVAT causes less pain and results in better cosmesis than conventional thyroidectomy [4].

\section{The anterior chest approach}

The anterior chest approach with $\mathrm{CO}_{2}$ insufflation involves three small ports on the anterior chest wall, comprising a 12-mm endoscope port and 5-mm ports for endoscopic instruments (Fig. 1C) [5]. A gasless anterior chest approach has also been developed using three ports on the anterior chest wall and the cervical region-lifting device without $\mathrm{CO}_{2}$ insufflation [6]. In another gasless anterior chest approach, the working space is created by $\mathrm{CO}_{2}$ insufflation, and an external retractor system is used to maintain it [7]. Video-assisted neck surgery involves a type of anterior chest approach or infraclavicular approach (Fig. 1D) [8] . A 3-4 cm main oblique incision is made in the anterior chest wall below the clavicle, and a 5 -mm incision is made in the lateral neck for inserting a 5-mm endoscope. After a skin flap has been dissected, two pieces of Kirschner wire are used to maintain the cervical working space without $\mathrm{CO}_{2}$ insufflation.

\section{The axillary approach}

The axillary approach with $\mathrm{CO}_{2}$ insufflation was developed by Ikeda et al. [9] in 2000, and uses three axillary incisions (Fig. 1E). A gasless transaxillary approach was developed later by Chung et al. $[10,11]$ and has gained in popularity. Initially the gasless transaxillary approach used a 6-cm axillary incision and one small anterior chest port (Fig. 1F), but it has progressed to using a single axillary incision without an anterior chest port (Fig. 1G) [12]. The gasless trans-axillary approach has also been modified in the form of a gasless unilateral axillary (GUA) approach (Fig. $1 \mathrm{H}$ ) and a gasless unilateral axillo-breast (GUAB) approach (Fig. 1I) by Tae et al. [13-16]. The GUAB approach makes use of a small breast port around the areola in addition to the axillary incision. The breast port provides a wide angle between the robotic or endoscopic instruments, making it easier to manipulate the instruments and avoid collisions. However, the robotic GUAB approach has evolved into the GUA approach without a breast port, for better cosmesis.

The gasless transaxillary approach is generally used for remote access thyroidectomy because of the good exposure and excellent surgical view of the thyroid gland and lateral neck. Also, total thyroidectomy and bilateral central neck dissection is possible through a unilateral axillary approach if it is performed by experienced surgeons, although dissection of the contralateral thyroid lobe and recurrent laryngeal nerve (RLN) is a little more difficult.

\section{The breast and axillo-breast approaches}

The breast approach using $\mathrm{CO}_{2}$ insufflation was developed by Ohgami et al. in 2000 (Fig. 1J) [18]. This approach uses two breast ports and one parasternal port $[18,19]$ and the scar in the 

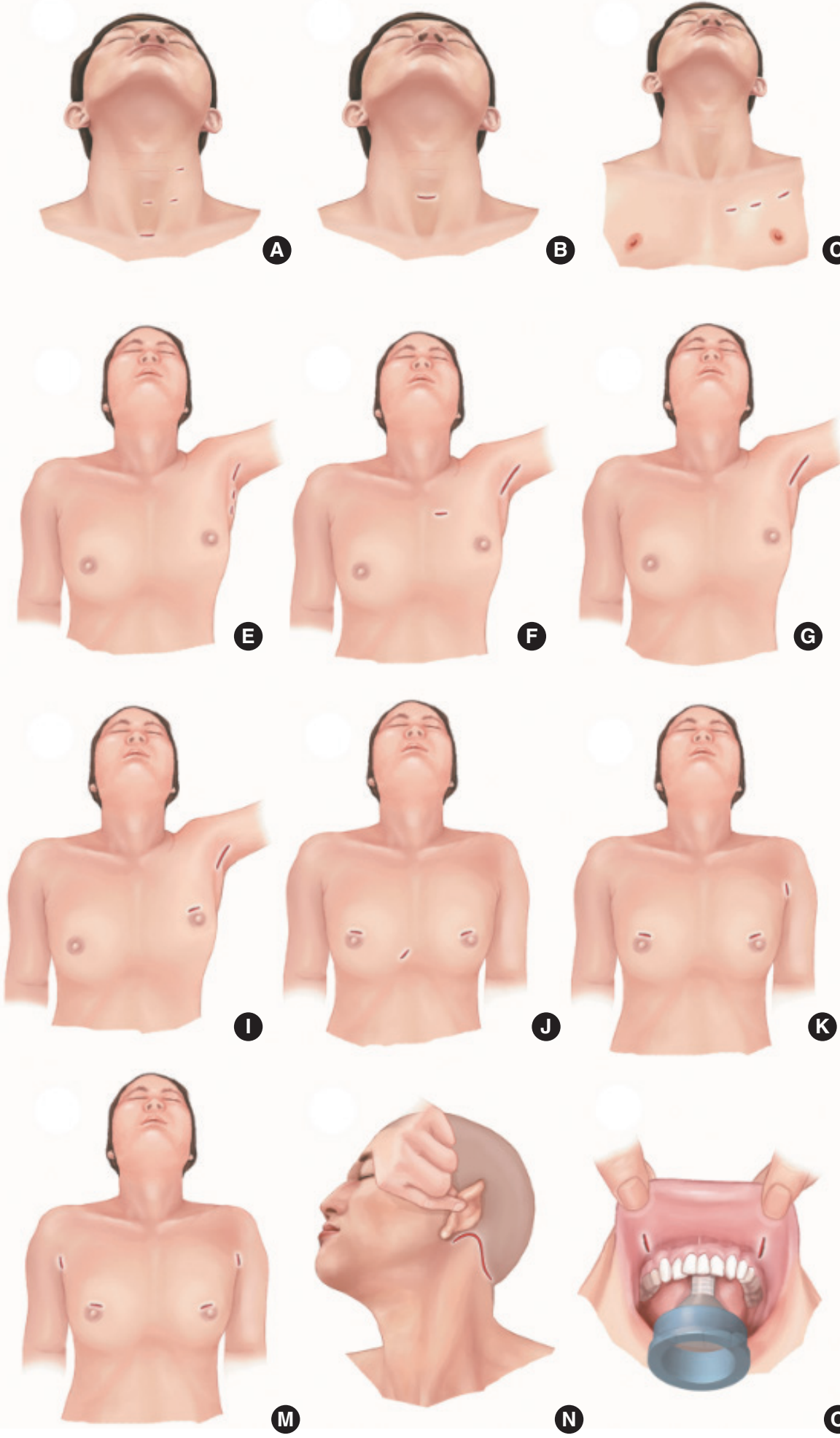

(1)
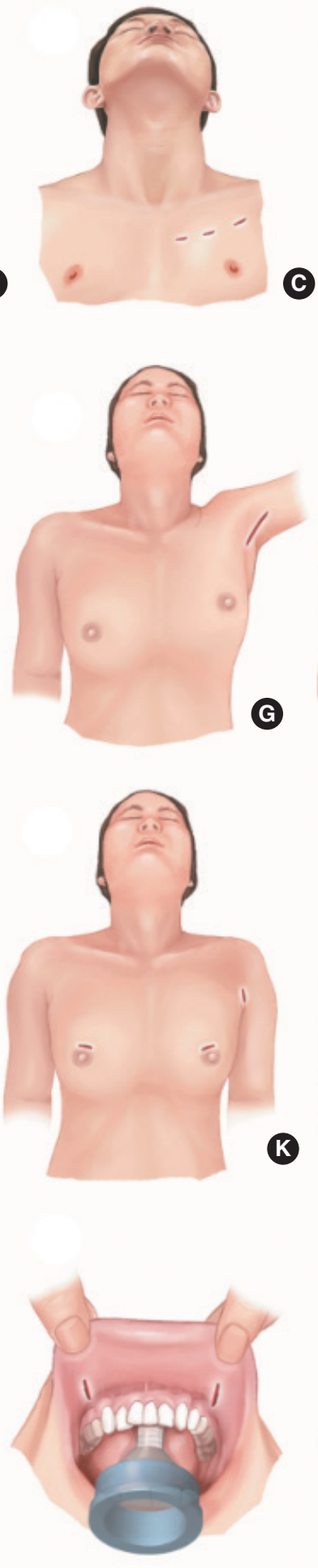

O
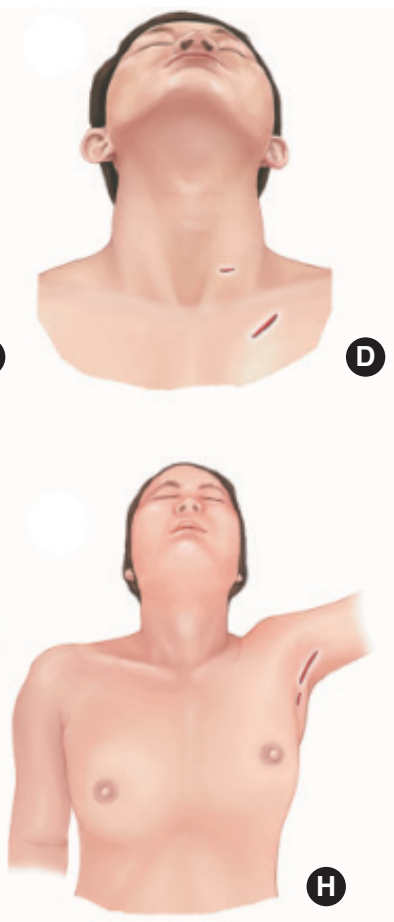

D

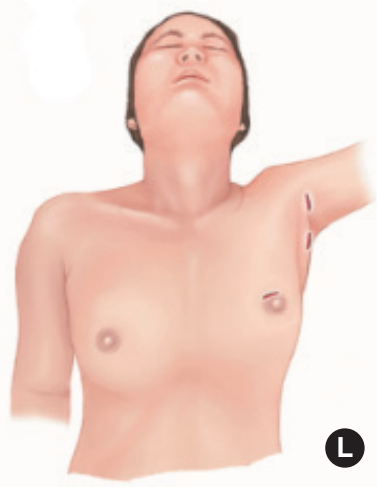

(ᄂ)

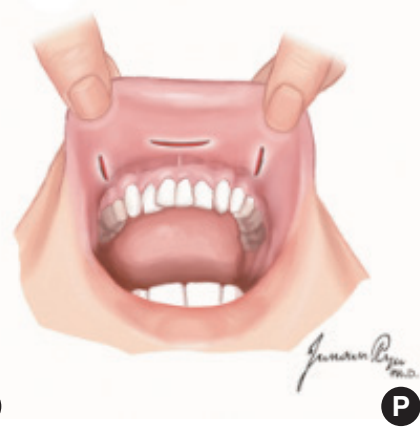

Fig. 1. Design of incisions in various robotic/endoscopic thyroidectomies. (A) Cervical approach with $\mathrm{CO}_{2}$ insufflation. (B) Minimally invasive video-assisted thyroidectomy. (C) Anterior chest approach with $\mathrm{CO}_{2}$ insufflation. (D) Video-assisted neck surgery. (E) Axillary approach with $\mathrm{CO}_{2}$ insufflation. (F) Gasless transaxillary approach with anterior chest port. (G) Single-incision transaxillary approach. (H) Gasless unilateral axillary approach. (I) Gasless unilateral axillo-breast approach. (J) Breast approach with $\mathrm{CO}_{2}$ insufflation. (K) Axillo-bilateral breast approach with $\mathrm{CO}_{2}$ insufflation. (L) Unilateral axillo-breast approach with $\mathrm{CO}_{2}$ insufflation. (M) Bilateral axillo-breast approach with $\mathrm{CO}_{2}$ insufflation. (N) Postauricular facelift approach. (O) Transoral sublingual and vestibular approach with $\mathrm{CO}_{2}$ insufflation. (P) Transoral vestibular approach with $\mathrm{CO}_{2}$ insufflation. 
parasternal area tends to hypertrophy. Therefore, various modifications have been developed to avoid a parasternal port by adding one or two axillary ports. The ABBA was developed by Shimazu et al. [20], and uses two breast ports and an axillary port (Fig. 1K) [20]. The unilateral or bilateral axillo-breast approaches with $\mathrm{CO}_{2}$ insufflation use one breast port and two axillary ports on one or both sides (Fig. 1L) [21]. The BABA was developed and popularized by Youn et al [22]. The BABA is a modification of the ABBA with an additional axillary port. It requires four incision sites, two in the areola, and an incision in each axillary area (Fig. 1M).

\section{The postauricular facelift approach}

Facelift (retroauricular) thyroidectomy was first developed by Terris et al. [24] using a surgical robot (Fig. 1N). However, it was mainly popularized by the Korean group, including Koh, Jung and Tae [25-27]. The postauricular facelift approach employs postauricular and occipital hairline incisions, and is familiar to head and neck surgeons as it is widely used in parotidectomies and to excise submandibular gland and neck masses [31-34]. It allows a smaller dissection area and a shorter distance from the incision site to the thyroid gland than the transaxillary approach [35]. Postoperative cosmesis is good, and the scar is concealed beneath the auricle and hair, particularly in female patients. The disadvantages of this approach are the narrow working space and the difficulty in approaching the contralateral thyroid lobe via the unilateral incision [27]. A contralateral postauricular incision is sometimes needed for contralateral lobectomy when the exposure of the contralateral lobe is inadequate.

\section{The transoral approach}

The transoral approach via a single sublingual route was initiated by Witzel et al. [36] in cadavers and the pig model. It includes a sublingual approach and an oral vestibular approach with or without $\mathrm{CO}_{2}$ insufflation [37-43]. Wilhelm et al. [40] and Wilhelm and Metzig [41] were the first to perform transoral thyroidectomy in humans, using one sublingual port and two oral vestibular ports (Fig. 10). The oral vestibular approach was described first by Richmon et al. [42] in a cadaveric model, and uses three oral ports in the oral vestibule. Nakajo et al. [43] also developed gasless transoral video-assisted neck surgery using a single $2.5-\mathrm{cm}$ incision in the oral vestibule.

Initially the transoral approach was considered difficult, due mainly to the limited working space, damage to the structure of the floor of mouth, hypoglossal nerve injury, and mental nerve injury. However, the transoral approach using three vestibular incisions has recently been revisited after a report of the use of the transoral endoscopic thyroidectomy vestibular approach in 60 human cases (Fig. 1P), and it is considered feasible and safe $[44,45]$. The transoral approach is viewed as a form of true natural orifice transluminal endoscopic surgery, and is less invasive in terms of working space than other types of remote access thyroidectomy. It makes it easier to perform total thyroidectomy than the transaxillary and facelift approaches because it provides midline access to both thyroid lobes. It also provides a top down operative view. Hence, central neck dissection can be performed easily up to levelVII.

\section{OPERATIVE PROCEDURES IN REMOTE ACCESS THYROIDECTOMY}

Of the various remote access thyroidectomy procedures, the gasless transaxillary approach, BABA, postauricular facelift approach, and transoral vestibular approach are widely used today. Below we describe these operative procedures briefly.

\section{The GUA approach}

The patient is placed in the supine position, the neck slightly extended, and the lesion-side arm is raised to expose the axillary fossa. A 5- to 6-cm skin incision is made in the axillary fossa $[15,16]$, and a skin flap is elevated under direct vision in the plane of the subplatysmal layer over the pectoralis major muscle from the axilla to the anterior neck area. The dissection is continued through the space between the two heads of the sternocleidomastoid (SCM) muscle and progressed below the sternothyroid muscle to expose the thyroid gland. Thereafter, an external retractor that is able to maintain adequate working space without $\mathrm{CO}_{2}$ insufflation is placed. A second 0.5 - or $0.8-\mathrm{cm}$ skin incision is made just inferior to the axillary incision to insert a trocar. The purpose of this second axillary incision is to minimize the length of the main axillary incision. Three robotic arms are then inserted through the main axillary incision port. A 30-degree face-down robotic endoscope is placed in the center of the main axillary port, and Prograsp forceps is placed at the top of the working space immediately below the external retractor blade and close to the endoscope. The Harmonic curved shears (dominant hand side) is placed at the right end of the main axillary incision, and a Maryland dissector (non-dominant hand side) is placed at the second axillary incision port in a leftside approach (Fig. 2).

The superior thyroid vessels are cut individually close to the thyroid gland, using the Harmonic curved shears, to preserve the external branch of the superior laryngeal nerve. The superior parathyroid gland is identified and is carefully preserved with an intact blood supply. The thyroid gland is then retracted medially, and the paratracheal lymph nodes and perithyroidal soft tissue are dissected while preserving the whole course of the RLN.The isthmus is divided, and the ipsilateral total lobectomy with central neck dissection is completed. A suction drain is inserted, and the wound closed.

\section{The bilateral axillo-breast approach}

The patient is placed in supine position, with neck extended us- 


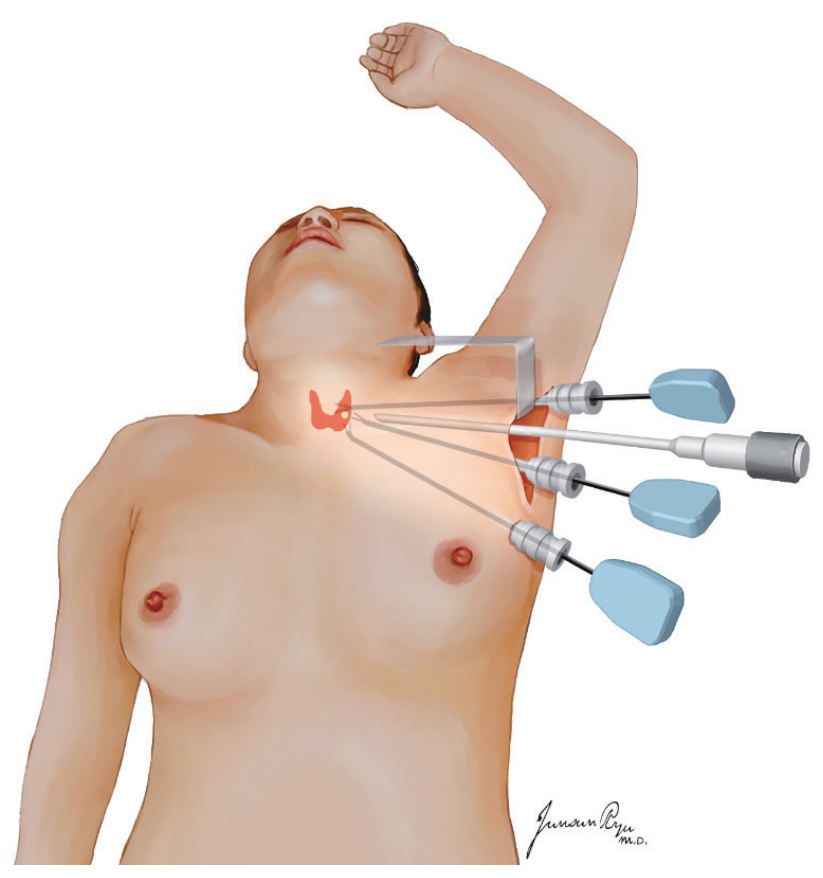

Fig. 2. The gasless transaxillary approach. After creating a working space, the endoscope and tree robotic instruments are placed as shown.

ing a shoulder pillow. Both arms are abducted slightly to insert the trocars $[22,46]$. Diluted epinephrine solution is injected into the subcutaneous space in both chest and neck to reduce bleeding during the dissection. After making incisions on both upper circumareolar areas, a blunt dissection is performed using a vascular tunneler. The working space is elevated to the level of the thyroid cartilage superiorly and to the medial border of the SCM muscle laterally. After creating an adequate working space, an endoscope is placed through the 12 -mm right breast port, and the left 12-mm breast port is used for the operating instruments. Two 5- or 8-mm cannulas are inserted through the axillae (Fig. 3). The working space is maintained using $\mathrm{CO}_{2}$ insufflation at a pressure of 5-6 $\mathrm{mmHg}$. The midline fascia between the strap muscles is divided, and the isthmus dissected. The thyroid gland is dissected, with preservation of the parathyroid glands and RLNs. The resected specimen is removed in a plastic bag through the $12-\mathrm{mm}$ breast port. The midline of the strap muscles is reapproximated, a suction drain is placed, and the skin is closed.

\section{The postauricular facelift approach}

A skin incision is made in the postauricular sulcus, curved posteriorly at the upper third of the auricle, and continued along the occipital hairline $[24,27]$. The skin flap is elevated in the plane of the subplatysma over the SCM muscle under direct vision, posteriorly to the posterior border of the SCM muscle, superior to the lower border of the mandible, and inferiorly to the sternal notch. The great auricular nerve and the external jugular

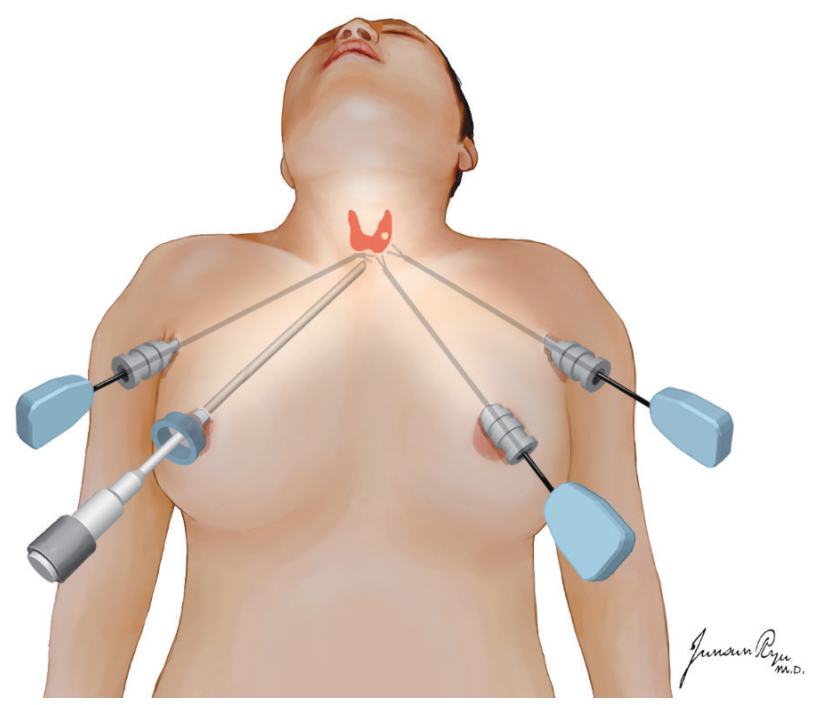

Fig. 3. The bilateral axillo-breast approach with $\mathrm{CO}_{2}$ insufflation. Four skin incisions are made; two in the areola and one in each axillary area.

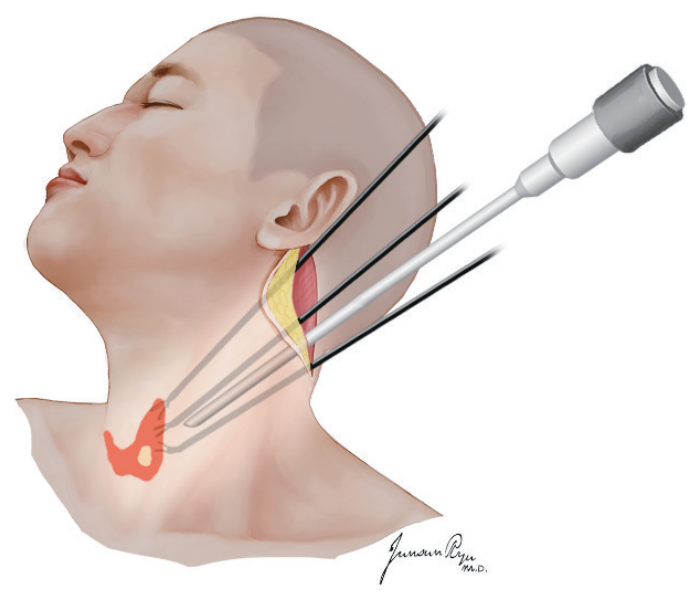

Fig. 4. The postauricular facelift approach. A 30-degree face-down endoscope and three robotic instruments, namely Maryland dissectors, Prograsp forceps and Harmonic curved shears, are inserted through the postauricular incision.

vein are identified and preserved. The omohyoid, sternohyoid and sternothyroid muscles are dissected and retracted upwards to expose the thyroid gland, after which an external retractor is placed to maintain the working space. A 30-degree face-down endoscope and three robotic instruments including Maryland dissectors, Prograsp forceps and Harmonic curved shears are inserted through the postauricular incision (Fig. 4). It is usually necessary to retract the SCM muscle and skin flap laterally, using a self-retaining retractor or an assistant to obtain an adequate working space. The parathyroid glands are identified and preserved, and the RLN is identified in the tracheoesophageal groove and preserved. The Berry's ligament and thyroid isthmus are dissected, and the lobectomy with isthmusectomy is com- 
pleted. A suction drain is placed, and the wound is closed layer by layer.

\section{The transoral vestibular approach}

The patient is placed in a supine position, and the neck is extended with a shoulder pillow under general anesthesia with orotracheal intubation [47]. A $1.5-2 \mathrm{~cm}$ horizontal incision is made at the end of the lower lip frenulum followed by lateral incisions on either side of the central incision, close to the oral commissure so as not to injure the mental nerve. Epinephrine diluted in normal saline is injected into the submental area for hydrodissection. Blunt dissection of the submental area is performed using a tunneler. A 30-degree rigid endoscope is placed in the center, and 5 or $8 \mathrm{~mm}$ trocars are inserted on either side of the endoscope for two endoscopic dissectors or monopolar electrocautery. The $\mathrm{CO}_{2}$ insufflation pressure is set at $5-6 \mathrm{mmHg}$. A working space is usually created in the plane of the subplatysmal layer by endoscopy without a surgical robot. The skin flap is widened to the level of the sternal notch inferiorly and the SCM muscle laterally. After completing the working space, a 30-degree robotic endoscope and robotic instruments such as bipolar Maryland's forceps or monopolar scissors are placed on either side of the endoscope (Fig. 5A). If necessary, a third robotic instrument such as Prograsp forceps or Cardinal forceps is inserted through the right axillary port (Fig. 5B). The midline fascia be- tween the strap muscles is divided and the sternohyoid and sternothyroid muscles are dissected to expose the thyroid gland. An external stitch is made to retract the strap muscles laterally for better surgical view. First the isthmus is dissected and divided, and then the thyroidectomy is performed while preserving the RLN and parathyroid glands. Special care must be taken to preserve the RLN when dissecting the Berry's ligament area. The specimen is removed using a plastic bag via the central oral incision. The divided strap muscles are re-approximated and the surgical wound in the oral vestibule is closed with absorbable sutures; usually no drain is required.

\section{INDICATIONS AND CONTRAINDICATIONS}

The indications for robotic and endoscopic thyroidectomy can be changed and expanded according to the experience of the surgeon, the disease status, and the approach itself. The indications may include follicular neoplasm or benign thyroid nodules less than 5-6 cm in diameter, and differentiated thyroid carcinoma less than 3-4 cm $[15,16]$. Also differentiated thyroid carcinoma with minimal extrathyroidal extension or invasion to the strap muscle, and even with metastasis to the central or lateral compartment lymph node, can be an indication. In the transoral approach, the size of the tumor or thyroid gland itself can influ-
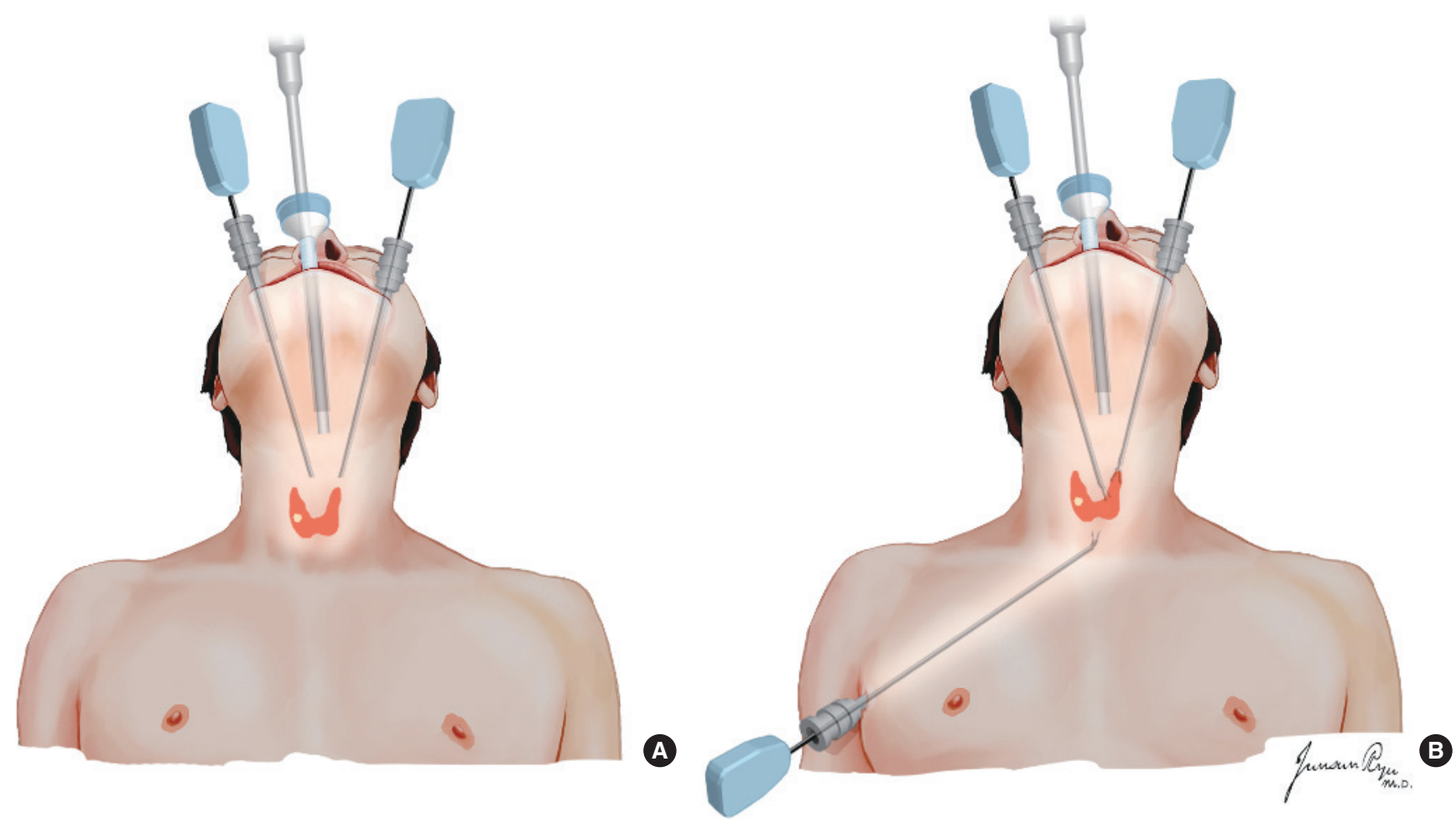

Fig. 5. The transoral vestibular approach with $\mathrm{CO}_{2}$ insufflation. (A) After creating a working space, a 30-degree robotic endoscope and two robotic instruments, such as bipolar Maryland forceps and monopolar scissors, are placed on either side of the endoscope. (B) Prograsp or Cardinal forceps is inserted through the right axillary port if necessary. 
ence the surgical indication because it is difficult to remove a large surgical specimen through a small oral incision port.

Exclusion criteria for robotic and endoscopic thyroidectomy include gross extrathyroidal extension, large conglomerated metastatic lymph nodes with invasion to the surrounding structures, large substernal goiters, a history of neck surgery or irradiation, and distant metastasis [15,16]. Large goiters with Grave disease or Hashimoto thyroiditis can be relative contraindications due to increased intraoperative bleeding and fragility of the thyroid tissue.

\section{COMPARISON OF REMOTE ACCESS THYROIDECTOMIES}

Each of the four most common remote access thyroidectomy procedures has its own advantages and disadvantages as shown in Table 2. Therefore, it is difficult to conclude which approach is best. Generally, $\mathrm{CO}_{2}$ insufflation methods have the advantage of exposing and maintaining the working space following a small skin incision made in a remote access site beyond the neck. Therefore, postoperative cosmesis may be better than in gasless methods that require long skin incisions at a remote site. However, $\mathrm{CO}_{2}$ insufflation can result in $\mathrm{CO}_{2}$-related complications such as subcutaneous emphysema, hypercapnia, respiratory acidosis, cerebral edema and $\mathrm{CO}_{2}$ embolism although there is low risk to patients if pressure levels of 4 to $6 \mathrm{mmHg}$ are used [47]. Gasless methods have the advantages of maintaining a clear surgical view without gas fumes, and the absence of complications related to $\mathrm{CO}_{2}$ insufflation. They also enable surgeons to use the conventional instruments employed in conventional thyroidectomy to dissect skin flaps and control bleeding.

Surgical invasiveness related to skin flap elevation is greatest in the BABA and transaxillary approach, and least in the tran-

Table 2. Comparison of remote access thyroidectomies

\begin{tabular}{lcccc}
\hline & $\begin{array}{c}\text { Gasless } \\
\text { axillary }\end{array}$ & BABA & $\begin{array}{c}\text { Gasless } \\
\text { facelift }\end{array}$ & Transoral \\
\hline $\begin{array}{lccc}\text { Invasiveness needed for } \\
\text { working space }\end{array}$ & ++++ & ++++ & +++ & ++ \\
$\begin{array}{l}\text { Manipulability of instruments } \\
\text { in working space }\end{array}$ & ++++ & +++ & +++ & +++ \\
$\begin{array}{l}\text { Operative time } \\
\text { Clarity of surgical view }\end{array}$ & +++ & ++++ & +++ & +++ \\
$\begin{array}{l}\text { Applicability of total } \\
\text { thyroidectomy }\end{array}$ & +++ & +++ & +++ & +++ \\
$\begin{array}{l}\text { Applicability of central neck } \\
\text { dissection }\end{array}$ & +++ & ++ & +++ & +++ \\
$\begin{array}{l}\text { Applicability of lateral neck } \\
\text { dissection }\end{array}$ & ++++ & ++ & +++ & + + \\
$\begin{array}{l}\text { Cosmetic satisfaction } \\
\text { Complication rate }\end{array}$ & + & & ++ & ++ \\
\hline
\end{tabular}

BABA, bilateral axillo-breast approach. soral approach, and the working space is widest in the transaxillary approach, making it easy to place and manipulate three robotic or endoscopic instruments. Clarity of surgical view is greater in gasless methods such as the gasless transaxillary and facelift approaches than in the BABA and transoral approaches. The BABA and transoral approach make it easier to perform total thyroidectomy than the trans-axillary and facelift approaches. However, the latter permit one to perform lateral selective neck dissection. Central neck dissection can be performed in all four approaches. However, it is relatively difficult in the BABA due to an inadequate angle of approach. Postoperative cosmesis is very good in all the procedures.

\section{ADVANTAGES AND LIMITATIONS OF REMOTE ACCESS THYROIDECTOMY}

Remote access thyroidectomy has many advantages. It provides excellent cosmesis and a magnified surgical view. In particular, robotic procedures using the da Vinci Surgical System (Intuitive Surgical, Sunnyvale, CA, USA) can provide a three-dimensional 10-12-fold magnified view, making it easy to identify the parathyroid glands and RLN. Unlike endoscopic thyroidectomy, robotic thyroidectomy also provides the ability to use three robotic instruments simultaneously, as well as fine motion scaling, hand-tremor filtering, innovative instrumentation with extended freedom of motion and surgical education $[15,48]$. The use of a 3rd robotic instrument is very important for obtaining counter traction, which facilitates dissection. Also, the robotic procedure does not require an assistant to hold the endoscope, so increasing the stability of the endoscope.

However, remote access thyroidectomy also has several disadvantages or limitations. It is not minimally invasive surgery in terms of skin flap elevation for creating the working space. However, it is also not maximally invasive surgery. It is just remote access surgery, and requires a wider dissection area to reach the thyroid gland. However, the thyroidectomy procedure itself is as refined as the conventional method. Some patients have complained of asymmetric and band-like contracture of the neck, anterior chest, and axillary area, which might be due to fibrotic contracture of soft tissue and muscles $[49,50]$. Bilateral and total thyroidectomies are rather difficult via unilateral transaxillary and facelift approaches although lobectomy can be done easily using these approaches. However, lobectomy is usually these days recommended for small, low-risk thyroid cancers, and this could provide a rationale for surgeons to consider facelift and transaxillary approaches. The high cost is another major drawback of robotic thyroid surgery [51-53]. It is a technically difficult procedure with a steep learning curve, which is an issue in terms of patient safety. 


\section{SURGICAL AND ONCOLOGIC OUTCOMES OF REMOTE ACCESS THYROIDECTOMY}

\section{Feasibility, safety, and complications}

Although there are many reports of the feasibility and safety of remote access thyroidectomy, complication rates are potentially higher, especially during the learning curve and in the case of low-volume surgeons because of the challenging surgical technique. There can also be serious complications such as injury to the esophagus and trachea, compromised airways due to hematomas, and, in rare instances, serious $\mathrm{CO}_{2}$ embolisms. Strict patient selection criteria are needed for successful surgical outcomes. The safety of patients must be the first priority, especially, during the steep learning curve. An appropriate training program for surgeons is also definitely required [28]. Also, the possibility of conversion to an open procedure should always be discussed with patients before surgery.

In meta-analyses, rates of complications such as RLN paralysis and hypoparathyroidism were not significantly different in robotic and conventional thyroidectomy [54-58]. However, in subgroup analyses, transient RLN paralysis was higher in the robotic procedure than the conventional procedure [55]; RLN injury, in particular, was more frequent early in the learning curve and with low-volume surgeons. Seroma is more often encountered in remote access surgery than in the conventional approach although it is easily controlled in the outpatient clinic by repeated aspiration $[15,16]$.

Unusual complications can also occur. Thus, transient brachial plexus injury has been reported in the robotic transaxillary approach [59], but the risk can be reduced by proper arm and shoulder positioning. Also the marginal branch of the facial nerve can be injured in the postauricular facelift approach, possibly as a result of compression of the nerve by a robotic instrument at the narrow postauricular port [27]. Mental nerve injury can also occur in the transoral approach [39], and $\mathrm{CO}_{2}$-related complications such as serious $\mathrm{CO}_{2}$ embolism can arise in procedures using $\mathrm{CO}_{2}$ insufflation [47].

\section{Operative time}

The operative time of robotic thyroidectomy is significantly longer than that of conventional thyroidectomy due to the longer flap dissection time and the time needed for robot docking [5458]. There was no significant difference of operative time between the transaxillary and the facelift approach in robotic thyroidectomy [27]. The average increase in operative time of robotic thyroidectomy compared to the conventional transcervical approach was 43.5 minutes [56]. However, operative time did not differ between robotic and endoscopic procedures [56]. The total operative time of robotic thyroidectomy may decrease with experience. Due to the complexities of flap dissection and manipulation of the robotic instruments, learning curve for robotic thyroidectomy via the transaxillary approach comprises
$35-50$ cases $[60,61]$, and the learning curve of the BABA is about 40 cases [62].

\section{Surgical completeness and number of lymph nodes removed} Complete total thyroidectomy via the unilateral gasless transaxillary and postauricular approaches is difficult because of the inadequate view of the contralateral lobe, and poor access to it. Therefore, the surgical completeness of total thyroidectomy can be an issue in robotic and endoscopic thyroidectomy. Thyrotropin-stimulated thyroglobulin ( $\mathrm{Tg}$ ) levels and radioactive iodine uptake levels are frequently-employed surrogate markers for the surgical completeness of total thyroidectomy. The surgical completeness of total thyroidectomy via the gasless transaxillary approach was similar to that of conventional thyroidectomy if it was performed by experienced surgeons [63]. However, in a meta-analysis, the pre-ablation-stimulated $\mathrm{Tg}$ level was significantly higher in robotic thyroidectomy than in conventional controls [64]. Also, the surgical completeness of the BABA was comparable to that of conventional thyroidectomy [65]. In a meta-analysis the number of lymph nodes retrieved in the robotic approach was significantly lower than in conventional thyroidectomy [64].

\section{Oncologic outcomes of thyroid cancer}

Oncologic outcome is an important issue in the treatment of thyroid cancer and should not be neglected or overlooked in favor of cosmesis or functional outcomes. However, the literature on oncologic outcomes such as locoregional recurrence and disease survival after robotic or endoscopic thyroidectomy is very limited. In three studies, oncologic outcomes, including diseasespecific survival and recurrence rates, were not significantly different in robotic trans-axillary thyroidectomy and conventional thyroidectomy although the follow-up period was rather short [66-68]. Further studies with long-term follow-up and large patient samples are needed to assess the ultimate long-term oncologic outcomes of robotic/endoscopic thyroidectomy.

\section{Cosmetic and functional outcomes and quality of life}

Cosmetic excellence is the most important reason for patients and surgeons to choose robotic/endoscopic thyroidectomy. Cosmetic outcome is indeed superior in robotic/endoscopic thyroidectomy than in conventional surgery $[15,57]$. Long-term cosmetic satisfaction after scar maturation is also significantly greater in the transaxillary approach than in conventional thyroidectomy [69].

In terms of voice outcomes, robotic thyroidectomy via the gasless transaxillary approach yielded better subjective voice recovery after surgery, and also better results for acoustic parameters of voice pitch than conventional surgery $[70,71]$. However, one study reported similar postoperative voice outcomes in transaxillary and conventional thyroidectomy [72]. Further prospective studies are needed to assess voice function after robotic 
and endoscopic thyroidectomy. Postoperative swallowing function after robotic/endoscopic thyroidectomy was also evaluated in some studies $[71,73]$. However, the evidence is not yet definitive.

Pain and sensory disturbance in the anterior chest area is more severe and lasts longer after gasless transaxillary thyroidectomy than after conventional thyroidectomy [17]. However, this disadvantage can be reduced by minimizing dissection of the anterior chest during flap elevation. Other studies reported no difference of subjective early postoperative pain in the robotic transaxillary approach and the conventional method [74,75].

Health-related quality of life after transaxillary robotic thyroidectomy, including physical, psychological, social, and spiritual well-being, was similar to that of patients undergoing conventional thyroidectomy [76].

\section{ROBOTIC LATERAL NECK DISSECTION}

Robotic and endoscopic thyroid surgery has been expanded to lateral neck dissection for thyroid cancers with lateral compartment lymph node metastasis. Robotic or endoscopic lateral neck dissection can be performed by a gasless transaxillary approach or postauricular facelift approach [77-79]. There is also a report of lateral neck dissection performed by the BABA with $\mathrm{CO}_{2}$ insufflation [80]. Ultrasound-guided charcoal tattooing prior to surgery is useful for identifying metastatic lymph nodes during robotic lateral neck dissection [81]. To date, there has been no long-term follow-up study after endoscopic/robotic lateral neck dissection, so its oncologic safety needs further evaluation.

\section{FUTURE SURGICAL ROBOTS FORTHYROID SURGERY}

The only surgical robot that has been used for thyroid surgery, the da Vinci Surgical System, is too big and bulky for remote access thyroid surgery since it is difficult to manipulate big robotic instruments in a narrow working space. There is also no haptic feedback. However, innovative technology will no doubt appear soon, and future surgical robots for robotic thyroid surgery may be flexible, smaller, and require only single-port access. They might also incorporate intraoperative neuro-monitoring, nonoptical viewing, haptic feedback, and a navigation system for the parathyroid glands, RLN, and lymph nodes. Such innovative surgical robots may make robotic thyroidectomy safer and more effective, and minimally invasive.

\section{CONCLUSION}

Robotic and endoscopic thyroidectomy using a remote access approach is feasible and comparable to conventional transcervical thyroidectomy in highly selected patients; it also yields excellent cosmesis. However, it has disadvantages in terms of longer operative time, higher cost, and technical difficulty. Strict patient selection criteria are very important. We also need to understand the advantages and limitations of various types of remote access thyroidectomy. Robotic thyroid surgery will no doubt progress as robotic technology evolves.

\section{CONFLICT OF INTEREST}

No potential conflict of interest relevant to this article was reported.

\section{REFERENCES}

1. Huscher CS, Chiodini S, Napolitano C, Recher A. Endoscopic right thyroid lobectomy. Surg Endosc. 1997 Aug;11(8):877.

2. Miccoli P, Berti P, Conte M, Bendinelli C, Marcocci C. Minimally invasive surgery for thyroid small nodules: preliminary report. J Endocrinol Invest. 1999 Dec;22(11):849-51.

3. Gagner M, Inabnet WB 3rd. Endoscopic thyroidectomy for solitary thyroid nodules. Thyroid. $2001 \mathrm{Feb} ; 11(2): 161-3$.

4. Miccoli P, Minuto MN, Ugolini C, Pisano R, Fosso A, Berti P. Minimally invasive video-assisted thyroidectomy for benign thyroid disease: an evidence-based review. World J Surg. 2008 Jul;32(7):133340.

5. Ikeda Y,Takami H, Tajima G, Sasaki Y,Takayama J, Kurihara H, et al. Total endoscopic thyroidectomy: axillary or anterior chest approach. Biomed Pharmacother. 2002;56 Suppl 1:72s-78s.

6. Kataoka H, Kitano H,Takeuchi E, Fujimura M.Total video endoscopic thyroidectomy via the anterior chest approach using the cervical region-lifting method. Biomed Pharmacother. 2002;56 Suppl 1:68s$71 \mathrm{~s}$.

7. Bae JS, Park WC, Song BJ, Jung SS, Kim JS. Endoscopic thyroidectomy and sentinel lymph node biopsy via an anterior chest approach for papillary thyroid cancer. Surg Today. 2009;39(2):178-81.

8. Shimizu K, Kitagawa W, Akasu H, Hatori N, Hirai K, Tanaka S. Videoassisted endoscopic thyroid and parathyroid surgery using a gasless method of anterior neck skin lifting: a review of 130 cases. Surg Today. 2002;32(10):862-8.

9. Ikeda Y, Takami H, Sasaki Y, Kan S, Niimi M. Endoscopic neck surgery by the axillary approach. J Am Coll Surg. 2000 Sep;191(3):33640.

10. Yoon JH, Park CH, Chung WY. Gasless endoscopic thyroidectomy via an axillary approach: experience of 30 cases. Surg Laparosc Endosc Percutan Tech. 2006 Aug;16(4):226-31.

11. Kang SW, Jeong JJ, Yun JS, Sung TY, Lee SC, Lee YS, et al. Robot-assisted endoscopic surgery for thyroid cancer: experience with the first 100 patients. Surg Endosc. 2009 Nov;23(11):2399-406.

12. Ryu HR, Kang SW, Lee SH, Rhee KY, Jeong JJ, Nam KH, et al. Feasibility and safety of a new robotic thyroidectomy through a gasless, transaxillary single-incision approach. J Am Coll Surg. 2010 Sep; 211(3):e13-9.

13. Tae K, Kim SY, Lee YS, Lee HS. Gasless endoscopic thyroidectomy by an axillary approach (preliminary report). Korean J OtolaryngolHead Neck Surg. 2007 Mar;50(3):252-6.

14. Tae K, Ji YB, Cho SH, Kim KR, Kim DW, Kim DS. Initial experience 
with a gasless unilateral axillo-breast or axillary approach endoscopic thyroidectomy for papillary thyroid microcarcinoma: comparison with conventional open thyroidectomy. Surg Laparosc Endosc Percutan Tech. 2011 Jun;21(3):162-9.

15. Tae K, JiYB, Jeong JH, Lee SH, Jeong MA, Park CW. Robotic thyroidectomy by a gasless unilateral axillo-breast or axillary approach: our early experiences. Surg Endosc. 2011 Jan;25(1):221-8.

16. Tae K, Ji YB, Cho SH, Lee SH, Kim DS, Kim TW. Early surgical outcomes of robotic thyroidectomy by a gasless unilateral axillo-breast or axillary approach for papillary thyroid carcinoma: 2 years' experience. Head Neck. 2012 May;34(5):617-25.

17. Song CM, Ji YB, Bang HS, Park CW, Kim H, Tae K. Long-term sensory disturbance and discomfort after robotic thyroidectomy. World J Surg. 2014 Jul;38(7):1743-8.

18. Ohgami M, Ishii S, Arisawa Y, Ohmori T, Noga K, Furukawa T, et al. Scarless endoscopic thyroidectomy: breast approach for better cosmesis. Surg Laparosc Endosc PercutanTech. 2000 Feb;10(1):1-4.

19. Park YL, Han WK, BaeWG. 100 Cases of endoscopic thyroidectomy: breast approach. Surg Laparosc Endosc Percutan Tech. 2003 Feb; 13(1):20-5

20. Shimazu K, Shiba E, Tamaki Y, Takiguchi S, Taniguchi E, Ohashi S, et al. Endoscopic thyroid surgery through the axillo-bilateral-breast approach. Surg Laparosc Endosc Percutan Tech. 2003 Jun;13(3):196201.

21. Lee MC, Mo JA, Choi IJ, Lee BC, Lee GH. New endoscopic thyroidectomy via a unilateral axillo-breast approach with gas insufflation: preliminary report. Head Neck. 2013 Apr;35(4):471-6.

22. Choe JH, Kim SW, Chung KW, Park KS, Han W, Noh DY, et al. Endoscopic thyroidectomy using a new bilateral axillo-breast approach. World J Surg. 2007 Mar;31(3):601-6.

23. Singer MC, Seybt MW, Terris DJ. Robotic facelift thyroidectomy. I. Preclinical simulation and morphometric assessment. Laryngoscope. 2011 Aug;121(8):1631-5.

24. Terris DJ, Singer MC, Seybt MW. Robotic facelift thyroidectomy. II. Clinical feasibility and safety. Laryngoscope. 2011 Aug;121(8):163641.

25. Byeon HK, Kim DH, Chang JW, Ban MJ, Park JH, Kim WS, et al. Comprehensive application of robotic retroauricular thyroidectomy: the evolution of robotic thyroidectomy. Laryngoscope. 2016 Aug; 126(8):1952-7.

26. Chung EJ, Park MW, Cho JG, Baek SK, Kwon SY, Woo JS, et al. A prospective 1-year comparative study of endoscopic thyroidectomy via a retroauricular approach versus conventional open thyroidectomy at a single institution. Ann Surg Oncol. 2015 Sep;22(9):3014-21.

27. Sung ES, Ji YB, Song CM, Yun BR, Chung WS, Tae K. Robotic thyroidectomy: comparison of a postauricular facelift approach with a gasless unilateral axillary approach. Otolaryngol Head Neck Surg. 2016 Jun;154(6):997-1004.

28. Perrier ND, Randolph GW, Inabnet WB, Marple BF, VanHeerden J, Kuppersmith RB. Robotic thyroidectomy: a framework for new technology assessment and safe implementation. Thyroid. $2010 \mathrm{Dec}$; 20(12):1327-32.

29. Hinson AM, Kandil E, O’Brien S, Spencer HJ, Bodenner DL, Hohmann SF, et al. Trends in robotic thyroid surgery in the United States from 2009 through 2013. Thyroid. 2015 Aug;25(8):919-26.

30. Park KN, Cho SH, Lee SW. Nationwide multicenter survey for current status of endoscopic thyroidectomy in Korea. Clin Exp Otorhinolaryngol. 2015 Jun;8(2):149-54.

31. Song CM, Jung YH, Sung MW, Kim KH. Endoscopic resection of the submandibular gland via a hairline incision: a new surgical approach. Laryngoscope. 2010 May;120(5):970-4.

32. Singh RP, Sung ES, Song CM, Ji YB, Tae K. Robot-assisted excision of the submandibular gland by a postauricular facelift approach: comparison with the conventional transcervical approach. Br J Oral
Maxillofac Surg. 2017 Dec;55(10):1030-4.

33. Song CM, JiYB, Kim KR, Tae K. Robot-assisted excision of branchial cleft cysts using a postauricular facelift approach. Auris Nasus Larynx. 2015 Oct;42(5):424-7.

34. Grover N, D'Souza A. Facelift approach for parotidectomy: an evolving aesthetic technique. Otolaryngol Head Neck Surg. 2013 Apr; 148(4):548-56.

35.Terris DJ, Singer MC. Qualitative and quantitative differences between 2 robotic thyroidectomy techniques. Otolaryngol Head Neck Surg. 2012 Jul;147(1):20-5.

36. Witzel K, von Rahden BH, Kaminski C, Stein HJ.Transoral access for endoscopic thyroid resection. Surg Endosc. 2008 Aug;22(8):1871-5.

37. Wang C, Zhai H, Liu W, Li J, Yang J, Hu Y, et al. Thyroidectomy: a novel endoscopic oral vestibular approach. Surgery. 2014 Jan;155(1): 33-8.

38. Fu J, Luo Y, Chen Q, Lin F, Hong X, Kuang P, et al. Transoral endoscopic thyroidectomy: review of 81 cases in a single institute. J Laparoendosc Adv Surg Tech A. 2018 Mar;28(3):286-91.

39. Kim HY, Chai YJ, Dionigi G, Anuwong A, Richmon JD. Transoral robotic thyroidectomy: lessons learned from an initial consecutive series of 24 patients. Surg Endosc. 2018 Feb;32(2):688-94.

40. Wilhelm T, Harlaar J, Kerver A, Kleinrensink GJ, Benhidjeb T. Transoral endoscopic thyroidectomy. Part 1: rationale and anatomical studies. Chirurg. 2010 Jan;81(1):50-5.

41. Wilhelm T, Metzig A. Endoscopic minimally invasive thyroidectomy (eMIT): a prospective proof-of-concept study in humans. World J Surg. 2011 Mar;35(3):543-51.

42. Richmon JD, Holsinger FC, Kandil E, Moore MW, Garcia JA, Tufano RP. Transoral robotic-assisted thyroidectomy with central neck dissection: preclinical cadaver feasibility study and proposed surgical technique. J Robot Surg. 2011 Dec;5(4):279-82.

43. Nakajo A, Arima H, Hirata M, Mizoguchi T, Kijima Y, Mori S, et al. Trans-oral video-assisted neck surgery (TOVANS): a new transoral technique of endoscopic thyroidectomy with gasless premandible approach. Surg Endosc. 2013 Apr;27(4):1105-10.

44. Anuwong A. Transoral endoscopic thyroidectomy vestibular approach: a series of the first 60 human cases. World J Surg. 2016 Mar;40(3): 491-7.

45. Anuwong A, Ketwong K, Jitpratoom P, Sasanakietkul T, Duh QY. Safety and outcomes of the transoral endoscopic thyroidectomy vestibular approach. JAMA Surg. 2018 Jan;153(1):21-7.

46. Lee KE, Rao J, Youn YK. Endoscopic thyroidectomy with the da Vinci robot system using the bilateral axillary breast approach (BABA) technique: our initial experience. Surg Laparosc Endosc Percutan Tech. 2009 Jun;19(3):e71-5.

47. Kim KN, Lee DW, Kim JY, Han KH, Tae K. Carbon dioxide embolism during transoral robotic thyroidectomy: a case report. Head Neck. 2018 Mar;40(3):E25-8.

48. Song CM, Cho YH, Ji YB, Jeong JH, Kim DS, Tae K. Comparison of a gasless unilateral axillo-breast and axillary approach in robotic thyroidectomy. Surg Endosc. 2013 Oct;27(10):3769-75.

49. Kwak DH, Kim WS, Kim HK, Bae TH. A band-like neck scar contracture after bilateral axillo-breast approach robotic thyroidectomy. Arch Plast Surg. 2016 Nov;43(6):614-5.

50. Kim JH, Park JW, Gong HS. Axillary web syndrome after transaxillary robotic thyroidectomy. J Robot Surg. 2014 Sep;8(3):281-3.

51. Berber E, Bernet V, Fahey TJ 3rd, Kebebew E, Shaha A, Stack BC Jr, et al. American thyroid association statement on remote-access thyroid surgery.Thyroid. 2016 Mar;26(3):331-7.

52. Broome JT, Pomeroy S, Solorzano CC. Expense of robotic thyroidectomy: a cost analysis at a single institution. Arch Surg. 2012 Dec; 147(12):1102-6.

53. Cabot JC, Lee CR, Brunaud L, Kleiman DA, Chung WY, Fahey TJ 3rd, et al. Robotic and endoscopic transaxillary thyroidectomies 
may be cost prohibitive when compared to standard cervical thyroidectomy: a cost analysis. Surgery. 2012 Dec;152(6):1016-24.

54. Jackson NR, Yao L, Tufano RP, Kandil EH. Safety of robotic thyroidectomy approaches: meta-analysis and systematic review. Head Neck. 2014 Jan;36(1):137-43.

55. Lang BH, Wong CK, Tsang JS, Wong KP, Wan KY. A systematic review and meta-analysis comparing surgically-related complications between robotic-assisted thyroidectomy and conventional open thyroidectomy. Ann Surg Oncol. 2014 Mar;21(3):850-61.

56. Kandil E, Hammad AY, Walvekar RR, Hu T, Masoodi H, Mohamed SE, et al. Robotic thyroidectomy versus nonrobotic approaches: a meta-analysis examining surgical outcomes. Surg Innov. 2016 Jun; 23(3):317-25.

57. Sun GH, Peress L, Pynnonen MA. Systematic review and metaanalysis of robotic vs conventional thyroidectomy approaches for thyroid disease. Otolaryngol Head Neck Surg. 2014 Apr;150(4):52032.

58. Liu SY, Ng EK. Robotic versus open thyroidectomy for differentiated thyroid cancer: an evidence-based review. Int J Endocrinol. 2016; 2016:4309087.

59. Kuppersmith RB, Holsinger FC. Robotic thyroid surgery: an initial experience with North American patients. Laryngoscope. 2011 Mar;121(3):521-6.

60. Lee J, Yun JH, Nam KH, Soh EY, Chung WY. The learning curve for robotic thyroidectomy: a multicenter study. Ann Surg Oncol. 2011 Jan;18(1):226-32.

61. Song CM, Jang YI, Ji YB, Park JS, Kim DS, Tae K. Factors affecting operative time in robotic thyroidectomy. Head Neck. 2018 May; 40(5):893-903.

62. Liu SY, Kim JS. Bilateral axillo-breast approach robotic thyroidectomy: review of evidences. Gland Surg. 2017 Jun;6(3):250-7.

63. Tae K, Song CM, Ji YB, Kim KR, Kim JY, Choi YY. Comparison of surgical completeness between robotic total thyroidectomy versus open thyroidectomy. Laryngoscope. 2014 Apr;124(4):1042-7.

64. Lang BH, Wong CK, Tsang JS, Wong KP, Wan KY. A systematic review and meta-analysis evaluating completeness and outcomes of robotic thyroidectomy. Laryngoscope. 2015 Feb;125(2):509-18.

65. Lee KE, Koo DH, Im HJ, Park SK, Choi JY, Paeng JC, et al. Surgical completeness of bilateral axillo-breast approach robotic thyroidectomy: comparison with conventional open thyroidectomy after propensity score matching. Surgery. 2011 Dec;150(6):1266-74.

66. Tae K, Song CM, Ji YB, Sung ES, Jeong JH, Kim DS. Oncologic outcomes of robotic thyroidectomy: 5-year experience with propensity score matching. Surg Endosc. 2016 Nov;30(11):4785-92.

67. Lee SG, Lee J, Kim MJ, Choi JB, Kim TH, Ban EJ, et al. Long-term oncologic outcome of robotic versus open total thyroidectomy in PTC: a case-matched retrospective study. Surg Endosc. 2016 Aug; 30(8):3474-9.

68. Sung TY, Yoon JH, Han M, Lee YH, Lee YM, Song DE, et al. Oncologic safety of robot thyroid surgery for papillary thyroid carcinoma: a comparative study of robot versus open thyroid surgery using inverse probability of treatment weighting. PLoS One. 2016 Jun;11(6): e0157345.

69. Ji YB, Song CM, Bang HS, Lee SH, Park YS, Tae K. Long-term cosmetic outcomes after robotic/endoscopic thyroidectomy by a gasless unilateral axillo-breast or axillary approach. J Laparoendosc Adv Surg Tech A. 2014 Apr;24(4):248-53.

70. Song CM, Yun BR, Ji YB, Sung ES, Kim KR, Tae K. Long-term voice outcomes after robotic thyroidectomy. World J Surg. 2016 Jan;40(1): 110-6.

71. Tae K, Kim KY, Yun BR, Ji YB, Park CW, Kim DS, et al. Functional voice and swallowing outcomes after robotic thyroidectomy by a gasless unilateral axillo-breast approach: comparison with open thyroidectomy. Surg Endosc. 2012 Jul;26(7):1871-7.

72. Lee J, Na KY, Kim RM, Oh Y, Lee JH, Lee J, et al. Postoperative functional voice changes after conventional open or robotic thyroidectomy: a prospective trial. Ann Surg Oncol. 2012 Sep;19(9):296370.

73. Lee J, Nah KY, Kim RM,Ahn YH, Soh EY, Chung WY. Differences in postoperative outcomes, function, and cosmesis: open versus robotic thyroidectomy. Surg Endosc. 2010 Dec;24(12):3186-94.

74. Ryu HR, Lee J, Park JH, Kang SW, Jeong JJ, Hong JY, et al. A comparison of postoperative pain after conventional open thyroidectomy and transaxillary single-incision robotic thyroidectomy: a prospective study. Ann Surg Oncol. 2013 Jul;20(7):2279-84.

75. Fregoli L, Materazzi G, Miccoli M, Papini P, Guarino G, Wu HS, et al. Postoperative pain evaluation after robotic transaxillary thyroidectomy versus conventional thyroidectomy: a prospective study. J Laparoendosc Adv SurgTech A. 2017 Feb;27(2):146-50.

76. Song CM, Ji YB, Bang HS, Park CW, Kim DS, Tae K. Quality of life after robotic thyroidectomy by a gasless unilateral axillary approach. Ann Surg Oncol. 2014 Dec;21(13):4188-94.

77. Kang SW, Lee SH, Ryu HR, Lee KY, Jeong JJ, Nam KH, et al. Initial experience with robot-assisted modified radical neck dissection for the management of thyroid carcinoma with lateral neck node metastasis. Surgery. 2010 Dec;148(6):1214-21.

78. Song CM, Ji YB, Sung ES, Kim DS, Koo HR, Tae K. Comparison of robotic versus conventional selective neck dissection and total thyroidectomy for papillary thyroid carcinoma. Otolaryngol Head Neck Surg. 2016 Jun;154(6):1005-13.

79. Kim WS, Koh YW, Byeon HK, Park YM, Chung HJ, Kim ES, et al. Robot-assisted neck dissection via a transaxillary and retroauricular approach versus a conventional transcervical approach in papillary thyroid cancer with cervical lymph node metastases. J Laparoendosc Adv Surg Tech A. 2014 Jun;24(6):367-72.

80. Seup Kim B, Kang KH, Park SJ. Robotic modified radical neck dissection by bilateral axillary breast approach for papillary thyroid carcinoma with lateral neck metastasis. Head Neck. 2015 Jan;37(1): 37-45.

81. Song CM, Park JS, Park W, Ji YB, Cho SH, Tae K. Feasibility of charcoal tattooing for localization of metastatic lymph nodes in robotic selective neck dissection for papillary thyroid carcinoma. Ann Surg Oncol. 2015 Dec;22 Suppl 3:S669-75. 